\title{
Deformation Localization and Damage Constitutive Model of Raw Coal and Briquette Coal under Uniaxial Compression
}

\author{
Lina Ge $\mathbb{D}^{1,2}$ Fu Yi $\mathbb{D}^{2}$ Changbo Du $\mathbb{D}^{1},{ }^{1}$ Junxia Zhou $\mathbb{D}^{2},{ }^{2}$ Zhenglong Cui $\mathbb{D},{ }^{1}$ \\ and Tao Wang $\mathbb{D}^{3}$ \\ ${ }^{1}$ School of Civil Engineering, Liaoning Technical University, Fuxin 123000, China \\ ${ }^{2}$ College of Architecture and Transportation, Liaoning Technical University, Fuxin 123000, China \\ ${ }^{3}$ School of Energy and Mining Engineering, China University of Mining and Technology (Beijing), 100083 Beijing, China
}

Correspondence should be addressed to Lina Ge; gln8223@163.com

Received 13 October 2021; Accepted 25 December 2021; Published 27 January 2022

Academic Editor: Yu Wang

Copyright ( 2022 Lina Ge et al. This is an open access article distributed under the Creative Commons Attribution License, which permits unrestricted use, distribution, and reproduction in any medium, provided the original work is properly cited.

\begin{abstract}
In order to compare and analyze the difference in deformation and damage law of soft and hard porous media materials, the digital image correlation is used to evaluate the heterogeneous development of strain fields of hard and brittle raw coal material and soft plastic briquette coal material under uniaxial compression. Through the defined statistical indicator, the quantitative characterization of deformation localization is realized, and the material damage constitutive model based on the statistical indicator of strain field is established. The results show that the yield stage of raw coal is not obvious, showing the characteristics of strain hardening and X-shaped macroscopic shear failure. The yield stage of briquette coal is more obvious, showing the characteristics of strain softening and a tensile failure mode. The progress of strain localization can well reflect the damage and destruction process of materials. The progress of strain localization of briquette coal can be divided into uniform deformation stage, localization stage, and failure stage, while the stage characteristics of localized evolution of raw coal is not obvious. The theoretical results of the damage constitutive model defined by statistical indicator are in good agreement with the experimental data and can well reflect the stress and strain characteristics of the two materials.
\end{abstract}

\section{Introduction}

Many disasters in geotechnical engineering can be attributed to the deformation and failure of materials. Mining engineering, tunnel engineering, hydropower engineering, etc. mostly realize early warning of engineering disasters by monitoring and analyzing the deformation process of coal, rock, and concrete. These are all porous materials, and their deformation is affected by various factors such as the initial damage state, strength, and the stress environment of the material. Studying the evolution process of the deformation field of porous media materials under the influence of different factors is of great significance for the early warning of engineering disasters and the analysis of instability mechanisms.

The destruction of materials is caused by the damage evolution process of nucleation, cracking, and expansion of the internal microstructure. The damage evolution process of materials has a certain correlation with the progress of localization of the surface deformation field, and the degree of damage and the destruction of materials can be reflected by the progress of material deformation localization $[1,2]$.

The digital speckle correlation method can obtain the deformation field by analyzing the speckle image of the specimen surface. Compared with other optical mechanical deformation measurement methods, the advantage of DSCM is that the required full-field deformation information of the specimen can be extracted directly from the natural or artificial speckle on the surface of the measured object without complex preprocessing. This technology has been widely used in fields such as material testing, fracture mechanics, and biomechanics.

Tang et al. used DIC (digital image correlation) technology to study the process of deformation and damage under 
different confining pressure conditions, analyzed the influence of confining pressure on stress threshold, energy evolution, strain evolution, and crack evolution, and proposed a method of confirming the stress level of localization initiation by the DIC technique [3]. Shirole et al. used the DIC method to observe the progress of the nonuniformity of the strain field on the surface of the rock sample and concluded that the heterogeneity of the strain field is a reflection of the inherent heterogeneity of the rock sample, and this heterogeneity is magnified as the stress on the rock sample increases [4]. Cheng et al. used 3D-DIC method and acoustic emission technology to reveal the strain and evolution characteristics of damage of composite rock specimens during uniaxial loading and proposed that the localized development of the maximum principal strain field can be used to predict the location of crack initiation and crack propagation process [5]. Périé et al. used the digital image correlation technique based on finite element discretization to extract the plane displacement field of anisotropic materials and then used the reconditioned equilibrium gap method to retrieve a damage law that accounts for shear softening [6]. Nguyen et al. used high-resolution digital photos and digital image correlation (DIC) technology to analyze the evolution process of inclined fractures in soft rock under compression and developed an extended DIC method to analyze the temporal and spatial evolution of fractures and provide experimental quantification of fracture patterns [7]. Wu et al. conducted a study on the deformation damage of rock-like specimens with different pores and different cracks at horizontal distances and found that the rock-like specimens exhibit notable progressive failure characteristics in the strain localization zones [8]. Munoz and Taheri used the DIC method to study the process of progressive damage evolution and localized evolution of sandstone during postpeak cyclic loading and concluded that as the number of loadingunloading cycles of rock samples increases, the accumulation of irreversible deformation and the degradation of the overall stiffness of the material are the reasons for the loss of the overall bearing capacity of the material [9].

With the help of digital image correlation, scholars all over the world have carried out a large number of studies on the deformation and damage process of coal and rock, which is mainly concentrated on the influence of changes in stress environment, initial damage, and other conditions on the evolution of coal and rock deformation fields, while there are few reports on the effect of softness and hardness on the progress of material deformation localization. In addition, the existing research mainly elaborates the relationship between the progress of strain localization and damage evolution from a qualitative or quantitative perspective, but the mechanism of damage evolution and strain localization is still unclear. The establishment of a constitutive model reflecting the mechanical characteristics of materials with the help of the evolution law of the deformation field needs further study.

In this paper, uniaxial compression tests of hard brittle raw coal and soft plastic briquette coal were carried out. With the aid of the DIC method, the difference between the evolution of strain field and the macroscopic failure mode of the two materials during the entire loading process was compared and analyzed. Based on the defined statistical indicator, the localized development processes of the two materials were quantitatively described, and finally, a damage constitutive model that can reflect the stress and strain characteristics of the two materials was established.

\section{Methods and Equipment}

2.1. Digital Image Correlation. Digital image correlation (DIC) was originally established independently by Professor Yamaguchi Ichiro of Japan and the research team of South Carolina University of the United States and was officially put forward in 1981 and 1982, respectively. The basic principle of DIC is to track (or match) the position of the same pixel in two speckle images before and after surface deformation of an object to obtain the displacement vectors of the pixels.

Using DIC method to measure displacement and deformation needs three steps: specimen and experimental preparation, image acquisition before and after loading, and digital image correlation calculation. The digital image correlation method calculates the displacement vector of each pixel by comparing the digital images of the tested surface in different states. Generally, the digital speckle image before deformation is called a reference image, and the digital speckle image after deformation is called a deformed image. Firstly, a square subimage with the size of $(2 N+1) \times(2 N$ +1 ) pixels is selected from the reference image centered on the point $P\left(x_{i}, y_{i}\right)$ to be measured, which is called reference subset, denoted by $f(x, y)$. At the same time, a square subimage with the size of $(2 M+1) \times(2 M+1)$ pixel (and $M>n$ ) is selected from the deformed image with the corresponding pixel as the center, which is called the searching subset. In the search subset, a subset of the same size as the reference subset is taken with each pixel as the center, which is called the deformed subset, denoted by $g\left(x^{*}, y^{*}\right)$. Then, the reference subset and each deformed subset in the searching set are correlated according to the predefined correlation function, and the position of the extreme point of the maximum or minimum correlation coefficient in the correlation coefficient distribution map corresponds to the position of the target subset. The difference between the coordinates of the center point $P^{\prime}\left(x_{i}{ }^{\prime}, y_{i}{ }^{\prime}\right)$ of the target subset and the center point of the reference subset is the displacement vector $d$ of the point $P\left(x_{i}, y_{i}\right)$ to be measured. Using the same method, the full-field displacement of the specimen surface can be obtained by performing the above operations on each pixel in the speckle image before and after deformation [10].

In the above correlation calculation process, the predefined correlation function is a function to evaluate the matching degree of the reference subset $f(x, y)$ and the deformed subset $g(x, y)$. Different correlation functions may lead to different calculation accuracy and convergence speed. In this paper, The calculation method of correlation coefficient selected in the calculation of digital speckle image is shown in Formula (1) [11]: 


$$
C(X)=\frac{\sum_{i=1}^{m} \sum_{j=1}^{m}\left[f\left(x_{i}, y_{j}\right)-\bar{f}\right] \cdot\left[g\left(x^{*}, y^{*}{ }_{j}\right)-\bar{g}\right]}{\sqrt{\sum_{i=1}^{m} \sum_{j=1}^{m}\left[f\left(x_{i}, y_{j}\right)-\bar{f}\right]^{2} \sum_{i=1}^{m} \sum_{j=1}^{m}\left[g\left(x^{*}{ }_{i}, y^{*}{ }_{j}\right)-\bar{g}\right]^{2}}} .
$$

$f(x, y)$ is the gray value of the reference image at coordinates $(x, y), g\left(x^{*}, y^{*}\right)$ is the gray value of the target image at coordinates $\left(x^{*}, y^{*}\right), \bar{f}, \bar{g}$ are the average gray values of images $f(x, y)$ and $g\left(x^{*}, y^{*}\right)$, respectively.

2.2. Measurement System. The measurement system used in this experiment is shown in Figure 1. As can be seen from Figure 1, the measurement system includes MTS servo press, CCD camera, LED fill light, image acquisition computer, and MTS servo press control computer. The press used in this test is MTS electronic servo testing machine with a range of $100 \mathrm{kN}$. Due to the limited range of the press, an electron-hydraulic servo universal testing machine with a range of $300 \mathrm{kN}$ is used when loading raw coal. In order to avoid the influence of the loading rate on the deformation field of the two types of coal and rock, the displacement loading mode is adopted, and the loading speed is set to $0.1 \mathrm{~mm} / \mathrm{min}$. Turn on the LED fill light before loading and adjust the position of the fill light to ensure uniform illumination on the sample surface, then adjust the focal length and position of the CCD camera to ensure that the surface of the sample captured by the camera is in the right position, and the image clarity meets the requirements of later calculations. During the loading process, the image acquisition computer acquires the image of sample surface in real time and automatically stores it. In order to reflect the real-time evolution process of coal and rock strain field, the camera acquisition rate should be set as high as possible under the condition of computer performance [12]. In this experiment, the image acquisition rate is set to 15 frames/s. The resolution of the CCD camera is 1280 pixel $* 1024$ pixel. After the test, the calculation program compiled by Matlab was used to obtain the displacement field and strain field of the surface of sample at different loading times. The digital speckle calculation adopts the calculation program based on Matlab software. During calculation, first select "reference image," select the size of the calculation area, and then, select "deformed image." The program calculates each "deformed image" and automatically saves the calculation results. The transverse displacement, vertical displacement, transverse shear strain, vertical shear strain, and maximum shear strain of the deformed image can be calculated at the same time.

\subsection{Preparation of Soft and Hard Porous Media Materials.} This paper uses hard and brittle raw coal samples and soft plastic briquette coal samples to reflect the deformation of soft and hard porous media materials. The raw coal samples were made according to the test method recommended by the International Society of Rock Mechanics. A large coal sample was taken on site and transported to the laboratory after being sealed. The wet processing method was used to obtain standard test pieces through core drilling, cutting, and smoothing. The size of prepared raw coal sample is 70 $\mathrm{mm} \times 70 \mathrm{~mm} \times 70 \mathrm{~mm}$ cubic specimen [13]. According to the research of literature [14], cement is used as binder in this test. Based on the obtained proportioning experience, considering that the initial ultrasonic wave velocity of briquette coal and raw coal is approximately equal, it is determined that the material mass ratio for briquette coal production is $m_{\text {pulverized coal }}: m_{\text {cement }}: m_{\text {water }}=10.0: 2.4$ : 1.6. The obtained raw coal is crushed into pulverized coal by crusher, and the pulverized coal with particle size less than $1 \mathrm{~mm}$ is selected for standby. The pulverized coal, cement, and water are evenly mixed according to the above proportion, put into the mold of the independently developed briquette preparation device, apply $20 \mathrm{MPa}$ pressure, and keep it constant for $20 \mathrm{~min}$, and then, demould. Put the demoulded briquette coal sample into the curing box for $28 \mathrm{~d}$, and the briquette samples are prepared. The prepared samples are shown in Figure 2. The speckle field was produced by manual spray painting on the surface of coal sample. In order to avoid the influence of primary crystal on the coal sample surface, the black spray paint was used to spray the coal sample surface evenly into black. After the spray paint was dry, the white spray paint was sprayed upward at a certain distance from the coal sample surface. After the white paint spots fell, they were scattered and attached to the coal sample surface to form the speckle field. The surface speckle field of coal sample produced by manual spray painting method is shown in Figure 2. Before the test, the speckle fields of 8 coal samples were made, including 4 raw coal samples and 4 briquette samples. After the speckle field was made, the loading test can be started.

\section{Test Results and Analysis}

3.1. Analysis of Stress-Strain Curve. By the displacement sensor of the testing machine, we obtained the stress and strain data of coal and rocks. Figure 3 shows the stress-strain curves of raw coal and briquette coal samples during indoor uniaxial compression. It can be seen from Figure 3 that the peak strength of raw coal is $42.69 \mathrm{MPa}$, the peak strength of briquette coal is $7.87 \mathrm{MPa}$, and the peak strength of raw coal is about 5 times that of briquette coal samples. The elastic modulus of raw coal is $1.4 \mathrm{GPa}$, the elastic modulus of briquette coal is $0.57 \mathrm{GPa}$, and the elastic modulus of raw coal is about 2.5 times that of briquette coal samples. The peak strain of raw coal is $4.2 \%$, the peak strain of briquette coal is $1.9 \%$, and the peak strain of raw coal is about 2.2 times that of briquette coal.

It can be seen from Figure 3 that the stress and strain curves of raw coal and briquette coal have gone through four stages, the initial compaction stage, the elastic deformation stage, the yield failure stage, and the postfailure stage. In the initial compaction stage, the stress-strain curves of the raw coal and briquette coal samples are both concave upwards, indicating that they both have initial microcracks and the compaction of micropore structure [15]. However, the strain value of the raw coal sample in the initial stage is obviously greater than that of the briquette coal sample; it is mainly because the raw coal has a structure rich in pores 


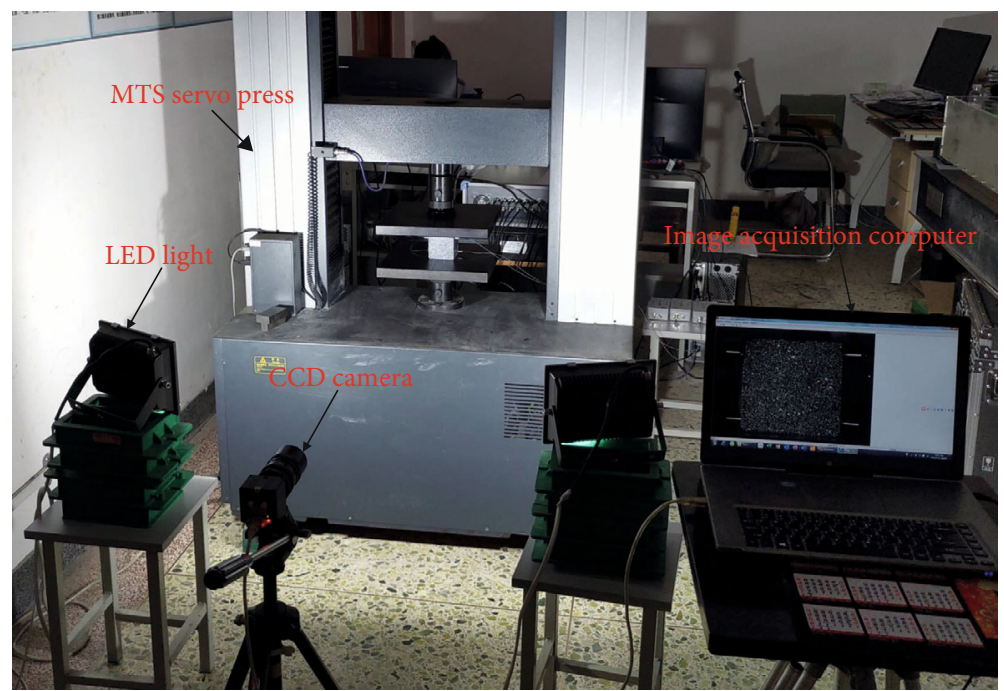

Figure 1: Actual picture of testing system.

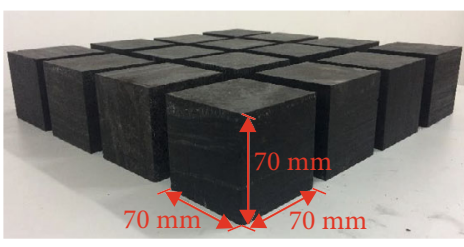

(a) Raw coal

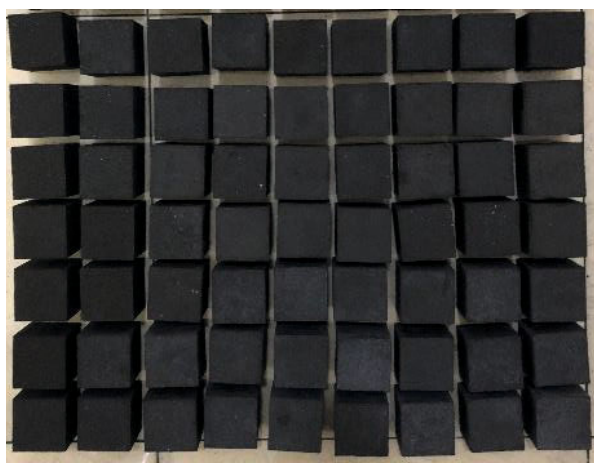

(b) Briquette coal

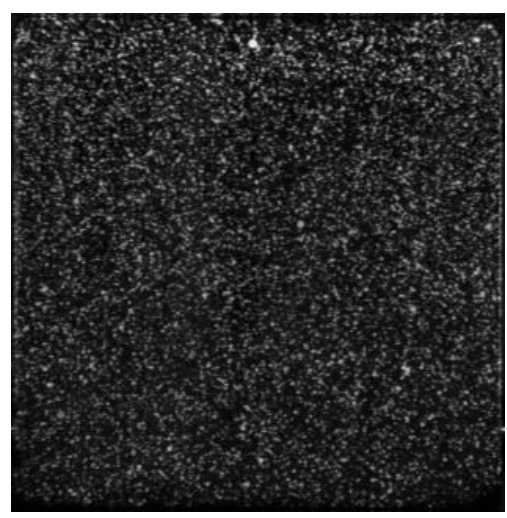

(c) Speckle field

Figure 2: Coal samples in testing.

and fissures, and the briquette coal sample is formed by pressing, and the internal pore structure has been basically compacted. In the elastic deformation stage, the stress and strain of raw coal and briquette coal samples both show a linear increase pattern. At this stage, the primary fractures of the raw coal sample are further closed, and the deformation can be recovered after unloading, which is manifested as elastic deformation. The briquette coal sample is mainly the extrusion of internal particles, and the deformation cannot be recovered after unloading, which is a linear deformation stage. In the stage of yield failure, the particle ejection phenomenon is shown during the loading process of the raw coal sample, accompanied by sound. Each particle ejection will cause fluctuations in the stress curve, and the stressstrain curve shows the characteristics of strain hardening. The stress of the briquette coal sample increases slowly with 


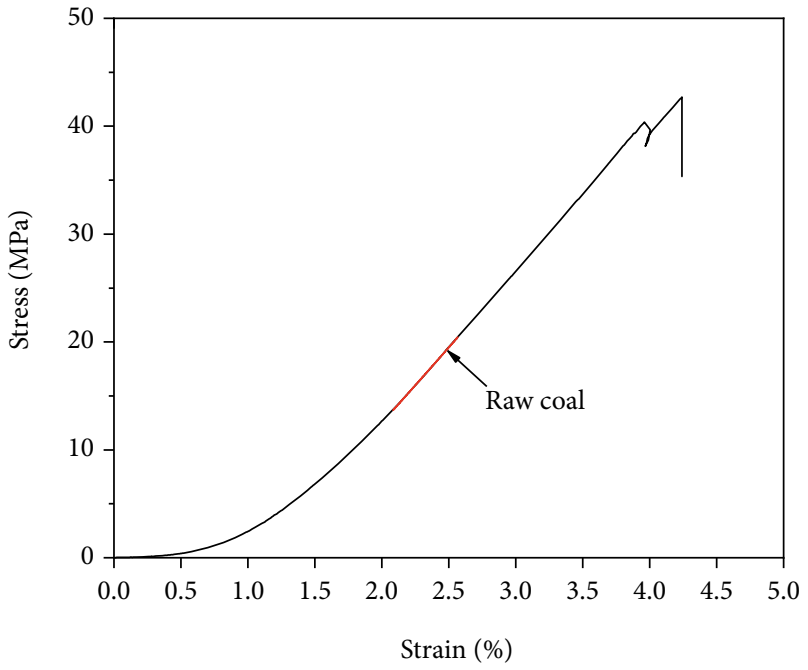

(a) Raw coal

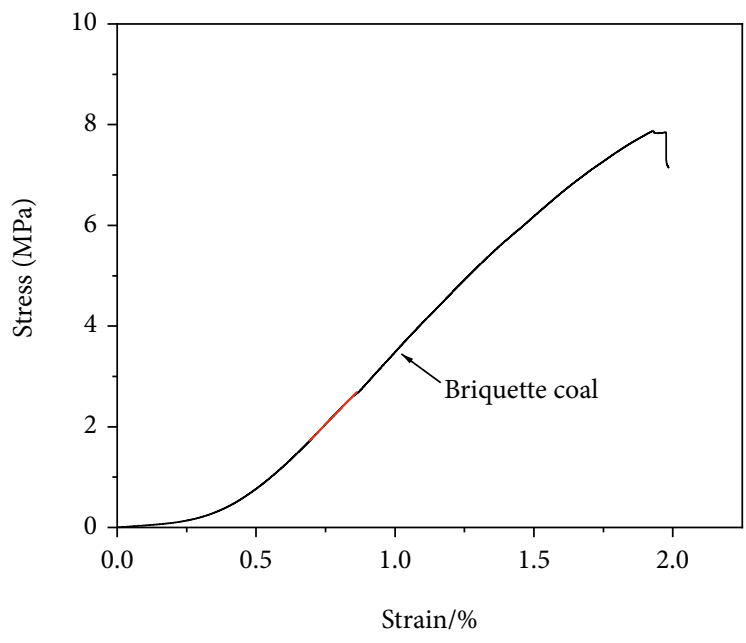

(b) Briquette coal

Figure 3: Stress-strain curves of raw coal and briquette coal.

the increase of the strain value and does not show the characteristics of particle ejection or sound during the loading process. The stress-strain curve is relatively smooth, with obvious plastic yield stage. In the postdestructive stage, when the stress reaches the peak strength, the raw coal is instantaneously destroyed, bursting into pieces with loud noises. The stress-strain curve shows a vertical drop, the briquette coal sample shows a slow failure state, and the stress-strain curve drops slowly, showing a characteristic of strain softening.

To compare and analyze the difference between the macroscopic failure modes of raw coal and briquette coal samples, Figure 4 shows the residual block after the raw coal is destroyed, and it also shows the coal image and the fullfield map of maximum shear strain field after the briquette coal is destroyed. It can be seen from Figure 4 that the distribution of strain localization zone on the surface of the sample obtained by the digital image correlation method is basically consistent with the crack distribution on the surface of the sample, which can reflect the damage process of the coal sample to a certain extent [8]. Figure 4(a) shows the cone-shaped block remaining after the destruction of the raw coal. According to the shape of residual block, the failure mode of raw coal can be determined as macroshear failure. Figure 4(b) shows the cracks distribution on the surface of the briquette coal after its failure, and the main control cracks of the briquette coal are located in the middle of the coal sample. The propagation direction is approximately parallel to the loading direction, and the briquette coal mainly undergoes tensile failure. Figure 4(c) shows the fullfield map of the maximum shear strain field of briquette coal, and an intermittent shear strain localization zone appears at the location of the main control crack. The combination of the above two can determine that the briquette coal mainly undergo tensile failure.

3.2. Analysis of the Evolution Law of Deformation Field. In order to analyze the evolution of the deformation field of soft and hard porous media with the increase of loading stress and the difference between the two, the characteristic points of different loading stages are selected, and the fullfield map of strain field is obtained by Matlab program. The information of the selected feature points at different loading stages are shown in Figure 5, and the full-field maps of the maximum shear strain field at each feature point are shown in Figure 6.

It can be seen from Figure 6 that the maximum shear strain values of the raw coal sample and the briquette coal sample both gradually increase with the increase of the loading stress value. In the initial compaction stage, the maximum shear deformation value of the hard-brittle coal sample at point $A$ is greater than that of the soft plastic briquette coal sample, and it is consistent with the law of the axial strain values of the two in the initial compaction stage. At the peak point $\mathrm{D}$, the maximum shear strain value of the hard-brittle coal sample is smaller than that of the soft plastic briquette coal sample. This is mainly because the hard and brittle raw coal sample is close to the macroscopic failure point at point $\mathrm{D}$, and the shear strain is stored inside the specimen in the form of energy. The damage is sudden and violent, and the digital speckle pattern collector does not capture the instantaneous damage process. However, there are obvious macroscopic failure cracks on the surface of the briquette coal sample at time $\mathrm{D}$, the shear strain concentration area is obvious, and the shear strain value is greater than that of the hard and brittle briquette coal sample. In Figure 6, point $A$ is at the initial compaction stage of the two samples. The maximum shear deformation value of the raw coal sample has an obvious localized zone of lateral deformation, because the raw coal sample has an initial crack at this position, and the cracks close first, resulting in obvious strain localization zone after the specimen is loaded. The numerical distribution of the maximum shear strain field on the surface of the briquette coal sample is relatively uniform, and no obvious strain localization zone is formed. 


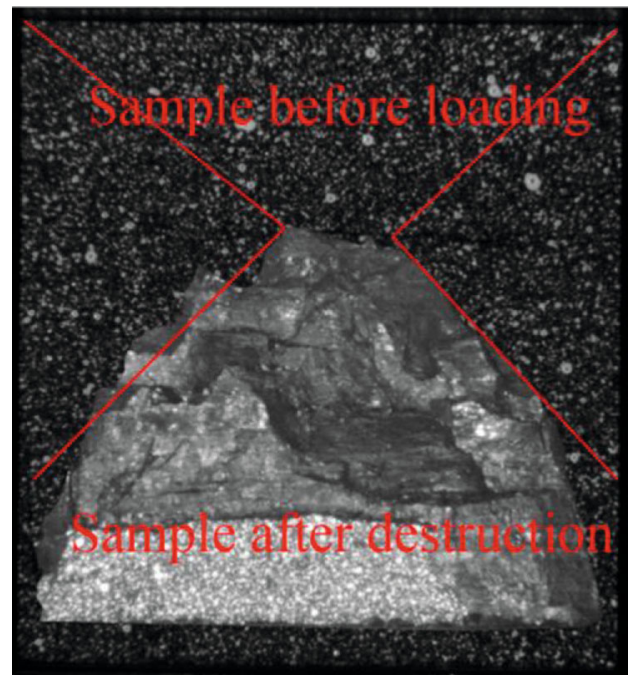

(a) Raw coal

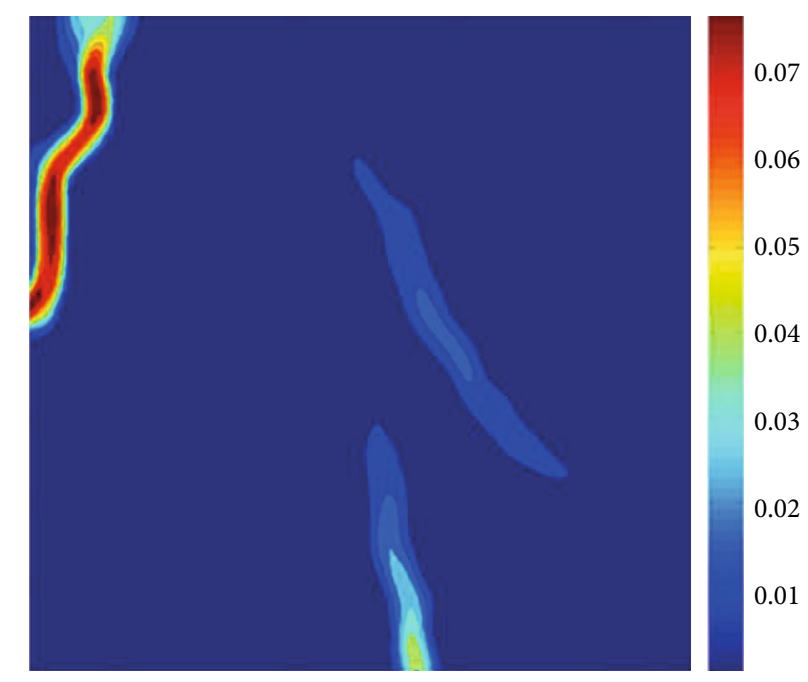

(c) Maximum shear strain

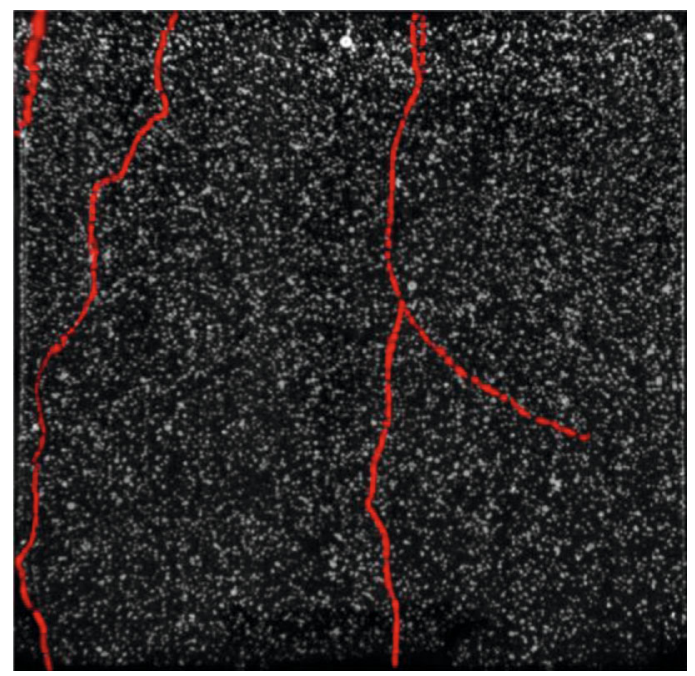

(b) Briquette coal

Figure 4: Failure modes of raw coal and briquette coal.

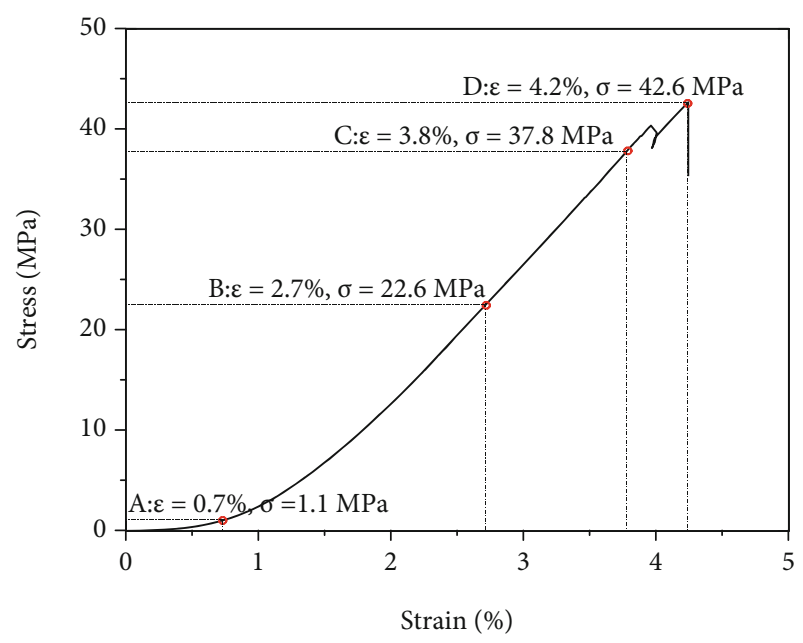

(a) Raw coal

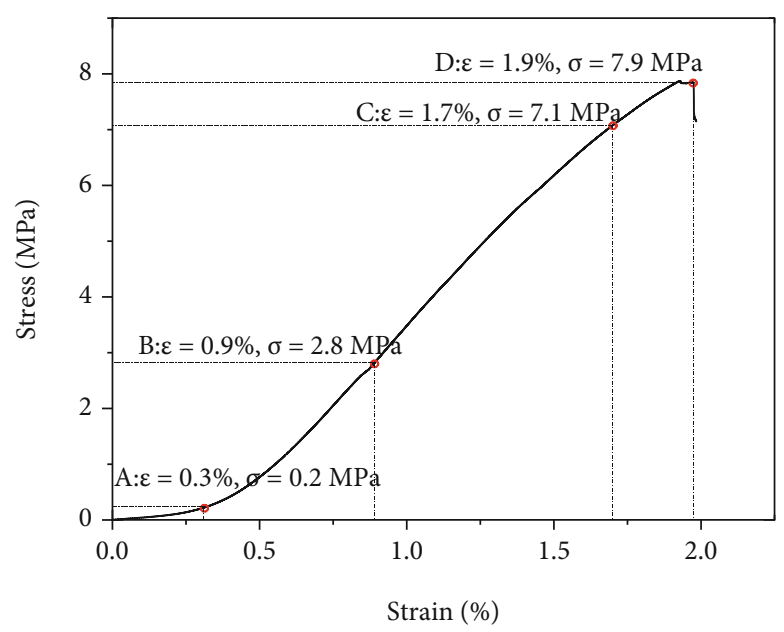

(b) Briquette coal

FIgURE 5: Stress-strain curves and observation times of coals. 

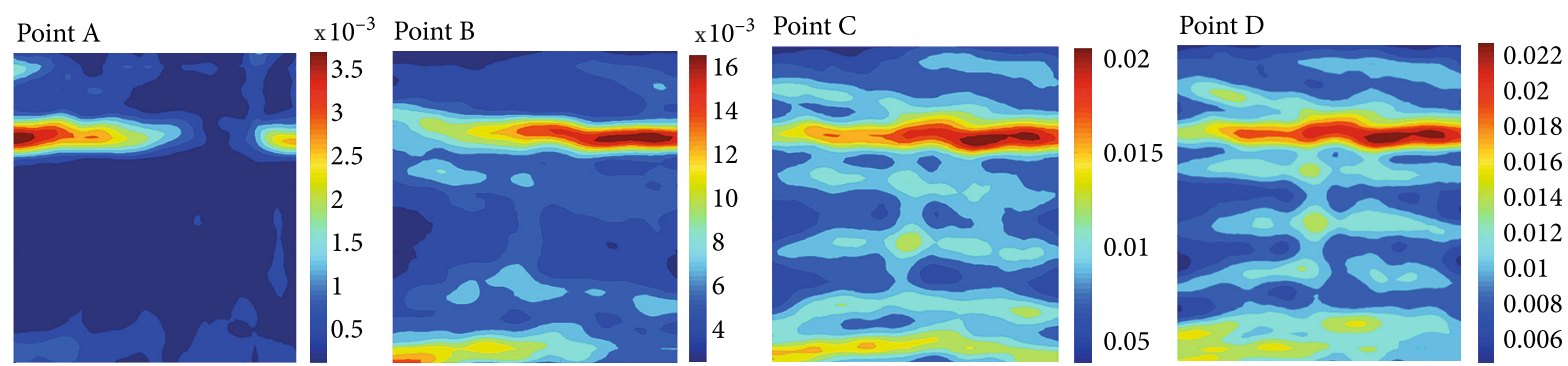

(a) Raw coal
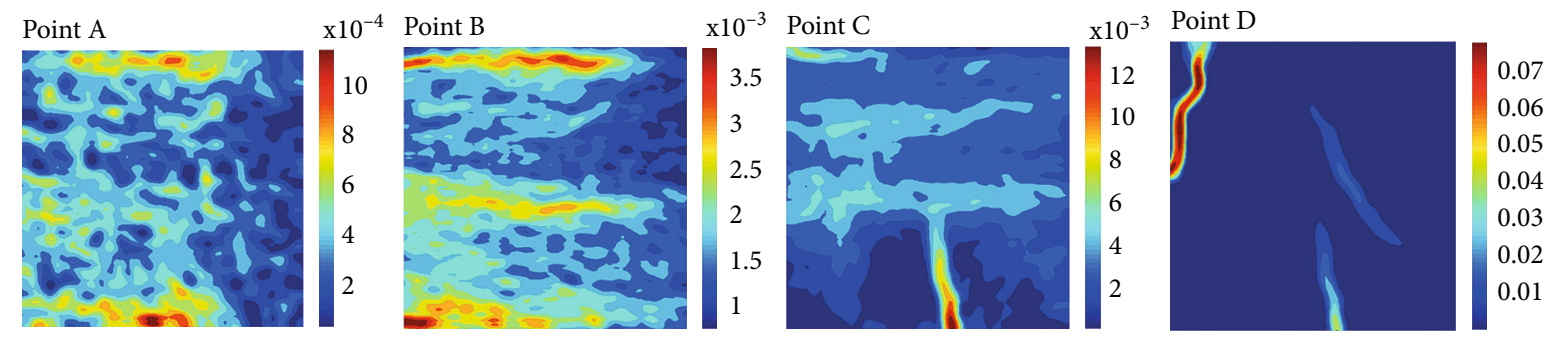

(b) Briquette coal

FIgURE 6: Strain fields at different loading stages.

The briquette coal sample is a compressed sample, with relatively uniform pore distribution inside it and no developed local cracks. The strain field does not show the strain concentration in the initial compaction stage. In Figure 6, point $\mathrm{B}$ is in the elastic deformation stage. Because the original pores and cracks in the sample have been basically closed in the initial compaction stage, the maximum shear deformation values of the two types of samples are uniformly increased. The difference of the maximum shear strain value in different areas of the sample surface gradually decreases, and the strain value tends to be uniform. Point $\mathrm{C}$ in Figure 6 is in the plastic yield stage. The maximum shear strain field on the surface of the hard and brittle raw coal sample shows several parallel distributed strain concentration zones, and the distribution of the maximum shear strain value is still relatively uniform. However, a vertical strain band has appeared in the lower part of the soft plastic briquette coal sample, and strain localization has begun to form, indicating that macroscopic cracks have formed at this stage. According to the expansion process of the strain localization zone, the cracks start from the end of the sample and expand in a direction parallel to the loading direction. In Figure 6 , when point $\mathrm{D}$ is at the peak point, the full-field map of the maximum shear strain field of the raw coal sample does not change too much compared with that at point $\mathrm{C}$, but only shows an increase in value. The full-field map of the maximum shear strain field of the briquette coal sample forms three obvious strain localization zones, which are mainly distributed in the upper left corner and the middle and lower positions of the sample and correspond to the macroscopic crack positions on the surface of the sample.

3.3. Localization of Starting Stress. The formation and evolution of the localized zone correspond to the formation and propagation of macroscopic cracks in the specimen [16]. Determining the formation time of the localized zone has important application value for the instability prediction and early warning of engineering rock mass. Literature quantitatively reflects the evolution law of material deformation field by introducing statistical indicator [16]. The statistical indicator is defined as

$$
S_{\mathrm{w}}=w_{s} * S^{\prime}
$$

where $S^{\prime}$ is the variance of deformation field at a certain time and $w_{s}$ is a weighting of "spatial features" of deformation localization.

$$
S^{\prime}=S^{\prime}\left(X_{k}\right)=\sqrt{\frac{1}{n-1} \sum_{k=1}^{n}\left(X_{k}-\bar{X}\right)^{2}},
$$

where $X_{k}$ is the strain value of each point ( $n$ points in total) in the deformation field; $\bar{X}$ is the average value of $X_{k}$, that is

$$
\begin{aligned}
& \bar{X}=\frac{1}{\mathrm{n}} \sum_{k=1}^{n} X_{k}, \\
& w_{s}=S^{\prime}\left(X_{k}^{*}\right)=\sqrt{\frac{1}{n-1} \sum_{k=1}^{n}\left(X_{\mathrm{k}}^{*}-\bar{X}^{*}\right)^{2}},
\end{aligned}
$$

where $X^{*}$ is the deformation field after "spatial processing" and the convolution of a matrix of strain values at each point of the deformation field and a matrix $B$ (convolution kernel) of size $m * m$ with all elements 1 , that is

$$
X^{*}=X \otimes B
$$


The statistical indicator $S_{w}$ can characterize the uneven degree of spatial distribution of deformation field values. When the deformation concentration of rock specimen occurs, the uneven degree of specimen surface deformation increases, and the slope of $S_{w}$ curve will have a large turning point. The turning point of $S_{w}$ curve can be used to judge the localization of rock deformation.

The full-field maps of maximum shear strain field at different loading moments were calculated by Matlab program, and the maximum shear strain values of different pixels on full-field map of maximum shear strain field was obtained with the help of Python language. According to the method provided by Wang et al., the statistical indicator values of the two materials during the process of uniaxial compression were calculated [16]. After normalizing the statistical indicator values, draw the relationship curves between statistical indicator and strain (as shown in Figure 7).

It can be seen from Figure 7 that the calculated statistical indicator values of the raw coal and briquette coal samples gradually increase with the increase of the axial strain value, and there is a certain difference between the increase methods of the two. With the increase of the strain value, the slope of the tangent line of the raw coal statistical indicator curve increases gradually, and the statistical indicator value increases slowly. However, the increase of the statistical indicator value of briquette coal can be divided into three stages, the linear increase stage, the steady increase stage, and the rapid increase stage. According to the evolution law of the statistical indicator curve, the position of the starting point of deformation localization can be calibrated according to the method in Sun et al. [17], and the localized starting stress of the material can be obtained accordingly. The starting stress of the raw coal sample is about $40.3 \mathrm{MPa}$, which is $94.4 \%$ of the peak stress. The starting stress of the briquette sample is about $6.7 \mathrm{MPa}$, which is about $85.1 \%$ of the peak stress. The soft plastic briquette sample is more prone to strain localization than the hard and brittle raw coal sample.

3.4. Establishment of Damage Constitutive Model Based on Statistical Indicator. According to the above research, the full-field map of the maximum shear strain field can reflect the failure process of the material to a certain extent. In this section, we intend to establish a damage constitutive model that reflects the damage and failure process of the material with the help of statistical indicator. Based on the concept of "continuity factor," Rabotnov defines the damage variable as $[18]$

$$
D=1-\frac{\tilde{A}}{A}
$$

In the formula, $A$ is the cross-sectional area of the nondestructive material, and $\tilde{A}$ is the effective bearing area of the damaged material.

Note that $\sigma_{i}$ is the nominal stress of the material, and $\tilde{\sigma}_{i}$ is the effective stress. Assuming that only the undamaged part inside the material can bear the load, the external force $F$ acting on the material can be expressed as

$$
F=\sigma_{i} A=\tilde{\sigma}_{i} \tilde{A}
$$

Combining formulas (3) and (4), it can be concluded that

$$
\sigma_{i}=\tilde{\sigma}_{i}(1-D)
$$

The effective stress cannot be directly determined by laboratory tests, but can only be obtained by establishing the relationship between the effective stress and other mechanical parameters measured in laboratory tests. Assuming that the part of the material that carries effective stress is an isotropic material, its deformation law satisfies Hooke's law, namely,

$$
\tilde{\sigma}_{i}=\tilde{E} \tilde{\varepsilon}_{i}+\tilde{\mu}\left(\tilde{\sigma}_{j}+\tilde{\sigma}_{k}\right)
$$

In the formula, $\tilde{E}$ is the elastic modulus of the undamaged part, $\tilde{\mu}$ is Poisson's ratio of the undamaged part, and $\tilde{\varepsilon}_{i}$ is the strain in the $\tilde{\sigma}_{i}$ direction, $i=1,2,3, j=3,1,2$, and $k=2,3,1$.

From formulas (5) and (6), it can be seen that

$$
\frac{\sigma_{i}}{1-D}=\tilde{E} \tilde{\varepsilon}_{i}+\tilde{\mu}\left(\frac{\sigma_{j}}{1-D}+\frac{\sigma_{k}}{1-D}\right) .
$$

The value of the elastic modulus $E$ can usually be expressed by the tangent modulus of the linear part of the stress-strain curve of the rock. When the damage model is established, the initial damage inside the material is not considered, so the initial compaction stage of the material stressstrain curve is ignored, and the material can be regarded as a nondestructive material. After being loaded, the material first exhibits elastic properties, then

$$
\tilde{E}=E
$$

Lemaitre puts forward the equivalent strain hypothesis that the strain caused by stress acting on damaged materials is equivalent to the strain caused by effective stress acting on nondestructive materials [19], which is

$$
\tilde{\varepsilon}_{i}=\varepsilon
$$

From the definition of Poisson's ratio, it can be seen that

$$
\tilde{\mu}=\left|\frac{\tilde{\varepsilon}_{3}}{\tilde{\varepsilon}_{1}}\right|=\left|\frac{\varepsilon_{3}}{\varepsilon_{1}}\right|=\mu .
$$

Combining formulas (11) (14), it can be concluded that

$$
\sigma_{i}=E \varepsilon_{i}(1-D)+\mu\left(\sigma_{j}+\sigma_{k}\right) .
$$

Formula (15) is the damage constitutive model under three-dimensional conditions. 


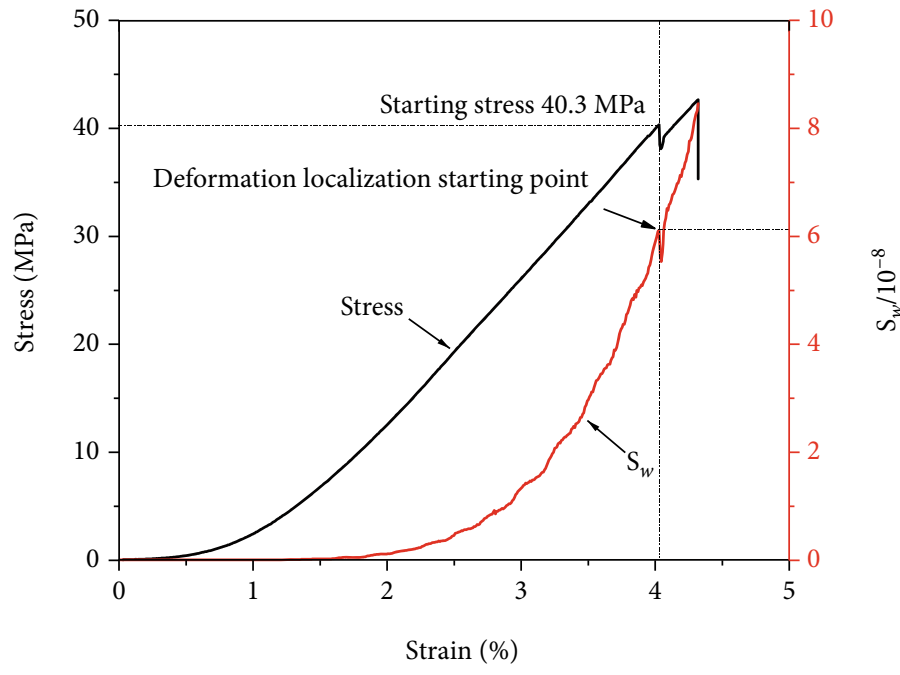

(a) Raw coal

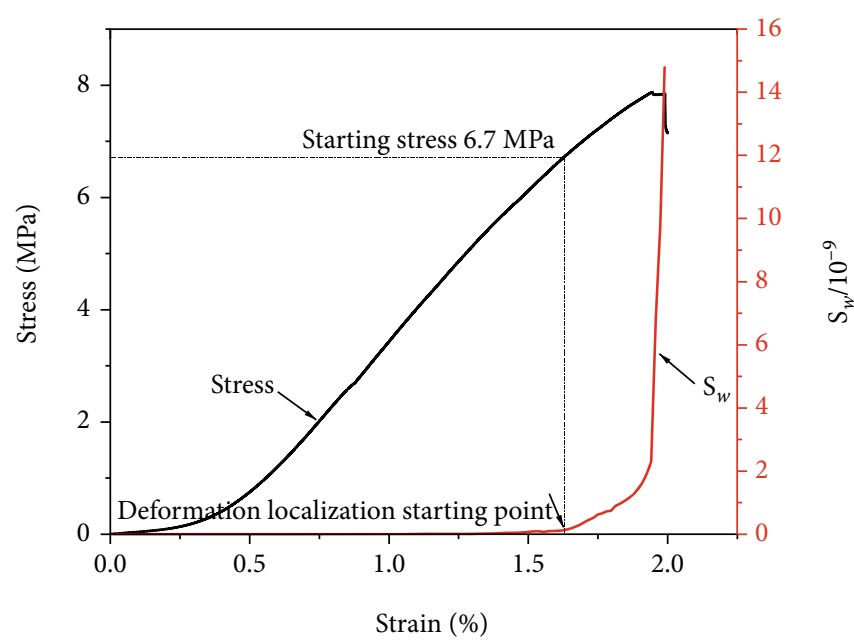

(b) Briquette coal

FIgURE 7: Statistical indicator curves.

It can be seen from formula (15) that the key to applying damage constitutive model is the determination of damage variable $D$. With the help of the idea of defining damage variable based on acoustic emission ringing count of Tang et al. [3], the damage variable is defined as follows:

$$
D=\lambda \frac{S_{n}}{S_{N}} .
$$

In the formula, $S_{n}$ is the cumulative value of the statistical indicator at a certain moment, $S_{N}$ is the cumulative value of the statistical indicator in the entire compression process, and $\lambda$ is the correction coefficient, which can be obtained by fitting.

Substituting formula (16) into (15), the damage constitutive model defined by statistical indicator can be obtained:

$$
\sigma_{i}=E \varepsilon_{i}\left(1-\lambda \frac{S_{n}}{S_{N}}\right)+\mu\left(\sigma_{j}+\sigma_{k}\right) .
$$

In particular, let $i=1, j=k=0$, the damage constitutive model can be defined based on statistical indicator under uniaxial compression:

$$
\sigma_{1}=E \varepsilon_{1}\left(1-\lambda \frac{S_{n}}{S_{N}}\right) .
$$

Formula (18) is based on the assumption that the material does not contain initial damage and does not consider the initial compaction stage in the actual process of the material. This paper considers the constitutive model of the material in compaction stage separately and gives a constitutive model reflecting the whole process of the material under load through a piece-wise function. Based on the effective medium theory, Peng et al. divided the axial strain into the axial strain of the material matrix and the axial strain of the crack and analyzed a large number of experimental data that the axial strain has a negative exponential function model with the axial stress of the material [20]. 


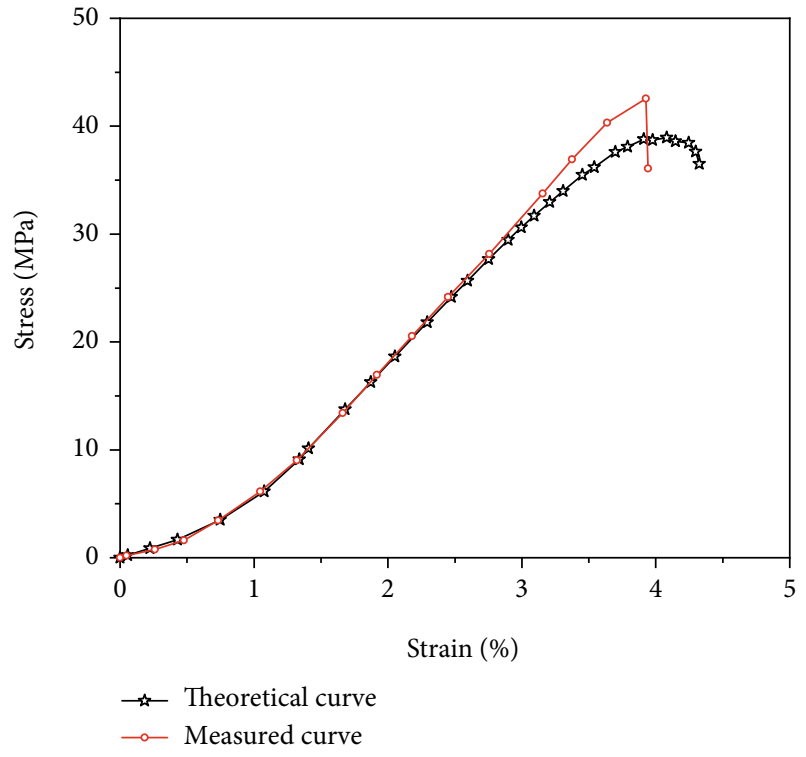

(a) Raw coal

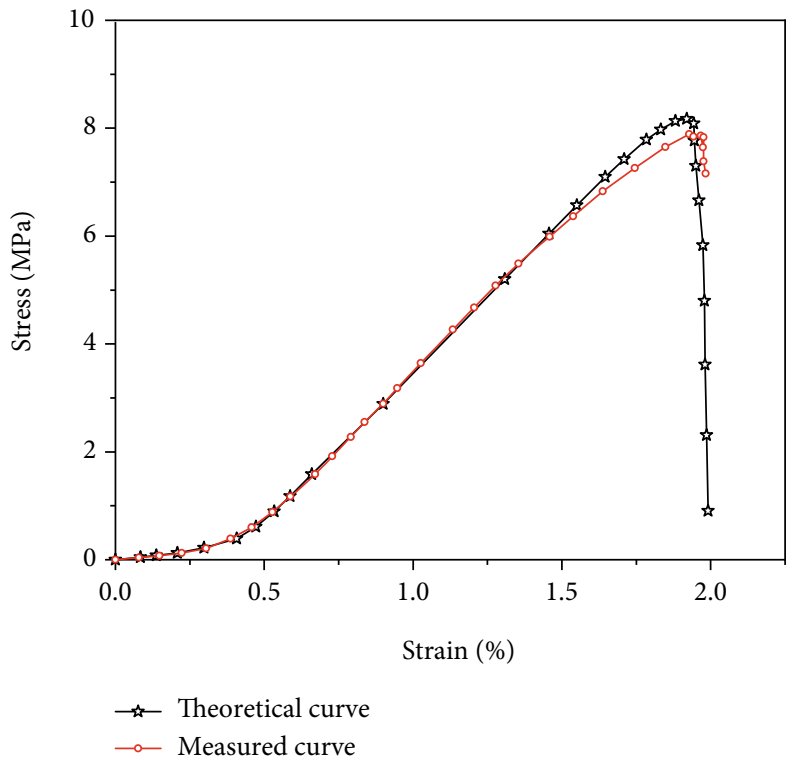

(b) Briquette coal

FIgURE 8: Comparison between experimental and theoretical stress-strain curves of raw coal and briquette coal.

Therefore, the constitutive model of the axial compaction stage under uniaxial compression can be expressed as

$$
\varepsilon_{1}=\frac{\sigma_{1}}{E}+V_{m}\left(1-e^{-\sigma_{1} / n}\right) .
$$

In the formula, $V_{m}$ is the model parameter, which represents the maximum axial closing strain of the crack, and $n$ is the model parameter, the unit is MPa.

Combining Equations (18) and (19), the damage constitutive model of the entire failure process under uniaxial compression can be obtained, namely,

$$
\begin{cases}\varepsilon_{1}=\frac{\sigma_{1}}{E}+V_{m}\left(1-e^{-\sigma_{1} / n}\right), & \varepsilon \leq \varepsilon_{0}, \\ \sigma_{1}=E\left(\varepsilon_{1}-\varepsilon_{c c}\right)\left(1-\lambda \frac{S_{n}}{S_{N}}\right), & \varepsilon>\varepsilon_{0} .\end{cases}
$$

In the formula, $\varepsilon_{0}$ is the strain value corresponding to the crack closure stress point; $\varepsilon_{c c}$ is the axial strain of the original crack of the material, which is the abscissa of the intersection point of the reverse extension line and the strain axis of the stress-strain curve in the elastic phase. The calculation formula is as follows:

$$
\varepsilon_{c c}=\varepsilon_{0}-\frac{\sigma_{c c}}{E}
$$

In order to verify the correctness of the damage constitutive model defined based on statistical indicator, the established damage constitutive model was used to fit the stressstrain curves of hard brittle raw coal material and soft plastic briquette material, respectively. The fitting results are shown in Figure 8, and the parameters in the model are shown in Table 1.
TABLE 1: Fitting parameters of theoretical model.

\begin{tabular}{lcccccc}
\hline $\begin{array}{l}\text { Material } \\
\text { type }\end{array}$ & $\begin{array}{c}\text { Coordinate of } \\
\text { stress point of } \\
\text { crack closure } \\
(\%, \mathrm{MPa})\end{array}$ & $\begin{array}{c}\text { Elastic } \\
\text { modulus } \\
(\mathrm{MPa})\end{array}$ & $\lambda$ & $\begin{array}{c}V_{m} \\
(\%)\end{array}$ & $\begin{array}{c}n \\
(\mathrm{MPa})\end{array}$ & $R^{2}$ \\
\hline Raw coal & $(1.27,8.45)$ & 1321 & 0.25 & 0.68 & 2.679 & 0.996 \\
$\begin{array}{l}\text { Briquette } \\
\text { coal }\end{array}$ & $(0.79,2.23)$ & 567 & 0.9 & 0.38 & 0.179 & 0.985 \\
\hline
\end{tabular}

It can be seen from Figure 8 that the damage model under uniaxial compression based on statistical indicator can well characterize the stress and strain characteristics of hard brittle coal materials and soft plastic coal materials. It can be seen from Figure 8(a) that the theoretical curve peak stress of the hard and brittle raw coal material is slightly lower than the peak strength of the material obtained in the test, which may be due to the sudden failure of the hard-brittle material when it reaches the peak. The CCD camera used in the experiment did not capture the instantaneous process of damage, which caused the calculation error of statistical indicator, thus affecting the fitting effect of the theoretical model.

\section{Conclusions}

In this work, the deformation-damage processes of hard and brittle coal samples and soft plastic briquette coal materials are studied with the help of digital image correlation measurement method; it can be concluded that:

(1) The uniaxial compression stress-strain curves of raw coal and briquette coal have typical four-stage characteristics. The hard and brittle raw coal material is 
not obvious in the later stage of loading, showing the characteristics of strain hardening, and the destruction is accompanied by loud noises, disintegrating into pieces and showing $\mathrm{X}$-shaped macroscopic shear failure. The yield stage of the soft plastic coal sample is obvious, showing the characteristics of strain softening, the main control crack is approximately parallel to the loading direction, and the failure mode is tensile failure

(2) The localization progress can reflect the damage process of materials. Soft plastic briquette coal materials are more likely to be localized than hard and brittle coal materials. The localization progress of briquette materials has typical phase characteristics, which can be divided into uniform deformation stage, localization stage, and destruction stage

(3) The statistical indicator curve of soft plastic briquette coal materials can be divided into linear increase stage, stable stage, and rapid increase stage. However, the statistical indicator of hard and brittle raw coal materials gradually increase with the increase of strain value, and they do not show stage characteristics. The localization starting point of briquette material is about $94.4 \%$ of the peak stress, and that of raw coal material is about $85.1 \%$ of the peak stress. Soft plastic materials are more prone to deformation localization

(4) Based on the statistical indicator, a damage constitutive model of materials under uniaxial compression is established. Through comparison and analysis with experimental data, the established model can simultaneously reflect the stress and strain characteristics of hard and brittle materials and soft plastic materials, which is more suitable for soft plastic materials than hard and brittle materials

\section{Data Availability}

The datasets used or analyzed during the current study are available from the corresponding author on reasonable request.

\section{Conflicts of Interest}

The authors declare that there is no conflict of interest regarding the publication of this paper.

\section{Acknowledgments}

This research was supported by Liaoning Provincial Department of Education Project (LJKZ0356 and LJ2020JCL037) and Discipline Innovation Team of Liaoning Technical University (LNTU20TD-26).

\section{References}

[1] D. Lei, Z. Huang, P. Bai, and F. Zhu, "Experimental research on impact damage of Xiaowan arch dam model by digital image correlation," Construction and Building Materials, vol. 147, pp. 168-173, 2017.
[2] D. Sokoli, W. Shekarchi, E. Buenrostro, and W. M. Ghannoum, "Advancing behavioral understanding and damage evaluation of concrete members using high-resolution digital image correlation data," Earthquakes and Structures, vol. 7, no. 5, pp. 609-626, 2014.

[3] Y. Tang, S. Okubo, J. Xu, and S. Peng, "Progressive failure behaviors and crack evolution of rocks under triaxial compression by 3D digital image correlation," Engineering Geology, vol. 249, pp. 172-185, 2019.

[4] S. Deepanshu, W. Gabriel, and H. Ahmadreza, "Experimental investigation of multi-scale strain-field heterogeneity in rocks," International Journal of Rock Mechanics and Mining Sciences, vol. 127, article 104212, 2020.

[5] J.-L. Cheng, S.-Q. Yang, K. Chen, D. Ma, F.-Y. Li, and L.M. Wang, "Uniaxial experimental study of the acoustic emission and deformation behavior of composite rock based on 3D digital image correlation (DIC)," Acta Mechanica Sinica, vol. 33, no. 6, pp. 999-1021, 2017.

[6] J. N. Périé, H. Leclerc, S. Roux, and F. Hild, "Digital image correlation and biaxial test on composite material for anisotropic damage law identification," International Journal of Solids and Structures, vol. 46, no. 11-12, pp. 2388-2396, 2009.

[7] T. L. Nguyen, S. A. Hall, P. Vacher, and G. Viggiani, "Fracture mechanisms in soft rock: identification and quantification of evolving displacement discontinuities by extended digital image correlation," Tectonophysics, vol. 503, no. 1-2, pp. 117-128, 2011.

[8] T. Wu, Y. Gao, Y. Zhou, and J. Li, "Experimental and numerical study on the interaction between holes and fissures in rock-like materials under uniaxial compression," Theoretical and Applied Fracture Mechanics, vol. 106, article 102488, 2020.

[9] H. Munoz and A. Taheri, "Local damage and progressive localisation in porous sandstone during cyclic loading," Rock Mechanics and Rock Engineering, vol. 50, no. 12, pp. 32533259, 2017.

[10] X. Y. Liu, Q. C. Tan, L. Xiong, and G. D. Liu, “A subpixel displacement estimation algorithm for digital image correlation based on a nonlinear intensity change model," Lasers in Engineering, vol. 23, no. 1-2, pp. 123-134, 2012.

[11] H. Song, H. Zhang, D. Fu et al., "Experimental study on damage evolution of rock under uniform and concentrated loading conditions using digital image correlation," Fatigue \& Fracture of Engineering Materials \& Structures, vol. 36, no. 8, pp. 760$768,2013$.

[12] Y. M. Song, T. Z. Xing, T. B. Zhao, Z. X. Zhao, and P. B. Gao, "Acoustic emission characteristics of deformation field development of rock under uniaxial loading," Chinese Journal of Rock Mechanics and Engineering, vol. 36, no. 3, pp. 534-542, 2017.

[13] T. Wang, H. Zhao, L. Ge, H. Zhang, and R. Liu, "Study on deformation evolution law of coal under asymmetric loading by digital image correlation," Applied Optics, vol. 59, no. 34, pp. 10959-10966, 2020.

[14] X. U. Jiang, Y. E. Gui-bing, L. I. Bo-bo, C. Jie, and Z. Min, "Experimental study of mechanical and permeability characteristics of moulded coals with different binder ratios," Rock and Soil Mechanics, vol. 36, no. 1, pp. 104-110, 2015.

[15] Y. Wang, B. Zhang, B. Li, and C. H. Li, "A strain-based fatigue damage model for naturally fractured marble subjected to freeze-thaw and uniaxial cyclic loads," International Journal of Damage Mechanics, vol. 30, no. 10, pp. 1594-1616, 2021. 
[16] Y. Wang, J. Q. Han, Z. Y. Song, and C. Zhu, "Macro-meso failure behavior of pre-flawed hollow-cylinder granite under multi-level cyclic loads: insights from acoustic emission and post-test CT scanning," Engineering Fracture Mechanics, vol. 258, article 108074, 2021.

[17] Q. Sun, C. Cai, S. K. Zhang et al., "Study of localized deformation in geopolymer cemented coal gangue-fly ash backfill based on the digital speckle correlation method," Construction Building Materials, vol. 215, pp. 321-331, 2019.

[18] Y. Rabotnov, "Creep rupture," Proceedings of the 12th International Congress of Applied Mechanics, M. Hetenyi and W. Vincenti, Eds., , pp. 342-349, Springer-Verlag, Berlin, Stanford, 1968.

[19] J. Lemaitre, "A continuous damage mechanics model for ductile fracture," Journal of Engineering Materials and Technology., vol. 107, no. 1, pp. 83-89, 1985.

[20] J. Peng, G. Rong, M. Cai, and C.-B. Zhou, "A model for characterizing crack closure effect of rocks," Engineering Geology, vol. 189, pp. 48-57, 2015. 